\title{
DESIGN OF MONITORING MOVEMENT PERSONNEL IN THE NIGHT DAY
}

\author{
Bovi Pasanenda ; Aries Boedi Setiawan
}

\begin{abstract}
Night patrols were conducted in groups of squads, a squad of ten men consisting of a squad commander and nine squad personnel. In an exercise or in the actual field of operation in the movement of a team, a squad leader is responsible for the movement of his personnel, for example in the movement of the squad on night patrols with dark conditions and limited visibility, the team commanders will have difficulty in monitoring their personnel one by one in the movements concurrent in a particular formation according to the instructions of the squad commanders. A commander is responsible for his personnel when one of his personnel is lost or lost. Because a squad commander in the field of operation or training should minimize both personnel and material losses.

To overcome this problem, a monitoring tool for the movement of squad personnel in night patrols utilizes the transmit distance from the XBee module and consists of a voltage-lowering circuit and a series of microcontrollers that act as an on-off controller on the led. The workings of this tool is based on microcontroller. The programming language used is the basic programming language compiler that is filled on an IC chip. The purpose of making this tool for the effectiveness of the use of electronic devices and reduce the loss of personnel and matrix in carrying out the actual training tasks and field operations tasks.

Based on the results of design, manufacture, testing and operation obtained minimal error so that it can be stated that the monitoring tool movement of personnel squads on night patrol can work in accordance with good conditions and can be applied into the actual form
\end{abstract}

Index Terms-XBee Module, Mikrocontroller, Led

\section{INTRODUCTION}

$\mathrm{N}$ ight patrols were conducted in groups of squads, a squad of ten people consisting of a squad commander and nine squad personnel. In an exercise or in actual operation a squad commander is responsible for both personnel and material loss. In the movement of the squads at night, for example, night patrols are very likely that a squad commander will lose his personnel. And apart from the team movement. With a javelin or frontal formation that requires personnel to move

Bovi Pasanenda, Electrical Engineering Department of Universitas Merdeka Malang, Malang, Indonesia

Aries Boedi Setiawan, Electrical Engineering Department of Universitas Merdeka Malang, Malang, Indonesia (+62 812-5289-217; individually at the same time and move in teams. It is very likely that a team member will be lost with limited visibility and that the movement should be quiet.

This is certainly related to how researchers create a control tool that can facilitate the performance of a squad commander and for the prevention of loss of personnel. So in the making of this thesis the author took the initiative to make a monitoring tool movement of personnel squads so as to facilitate the execution of duties komadan squad field.

\section{FUNDAMENTAL}

\subsection{XBee Module.}

XBee wireless module or often called a zigbee module is a transceiver module. Radio frequency transceiver or radio frequency transmitter and receiver functions for full duplex communication. One of the $2.4 \mathrm{GHz}$ wireless communication modules is XBee OEM ZigBee / IEEE 802.15.4 2.4 GHz. Radio frequency transceiver is a module consisting of RF transmitter and RF receiver with UART (Universal Asynchronous Receiver Transceiver) serial interface system. Here is a picture of Xbee module:

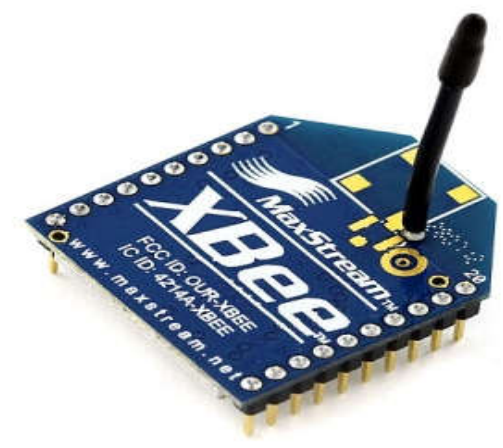

Fig 1. XBee Module

\subsection{Microcontroller ATmega8.}

AVR ATmega 8 is mikrocontroller 8-bit CMOS AVR RISC architecture that has $8 \mathrm{~K}$ bytes in-System Programmable Flash. Microcontrollers with low power consumption are able to execute instructions with a maximum speed of 16 MIPS at a frequency of $16 \mathrm{MHz}$. When compared with ATmega $8 \mathrm{~L}$ the difference lies only in the amount of voltage required to work. For ATmega 8 type L, the microcontroller can work with voltages between $2.7-5.5 \mathrm{~V}$ while for ATmega 8A can only work on voltages between 4.5-5.5 V. 
ATmega8 Pins.

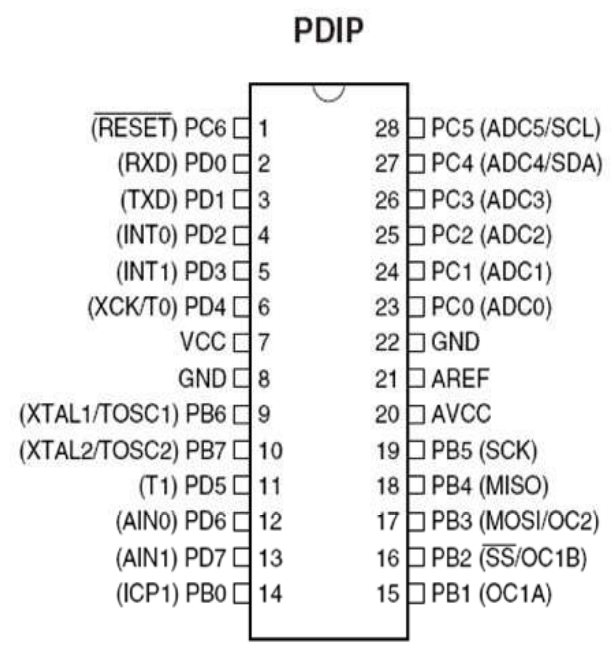

Fig 2 Configuration ATmega8 Mikrocontroller Pin ( Image from AVR ATmega8, www.alldatasheet.com )

\subsection{BASCOM AVR}

BASCOM AVR is a compiler software using basic language developed and issued by MCS Electronic. BASCOM AVR Made for programming on AVR family microcontroller. BASCOM AVR is a compiler software using basic language developed and issued by MCS Electronic. BASCOM AVR Made for programming on AVR family microcontroller.

\section{METHODS}

\subsection{System Planning}

To facilitate the design, required block diagram shown in Figure 3.1

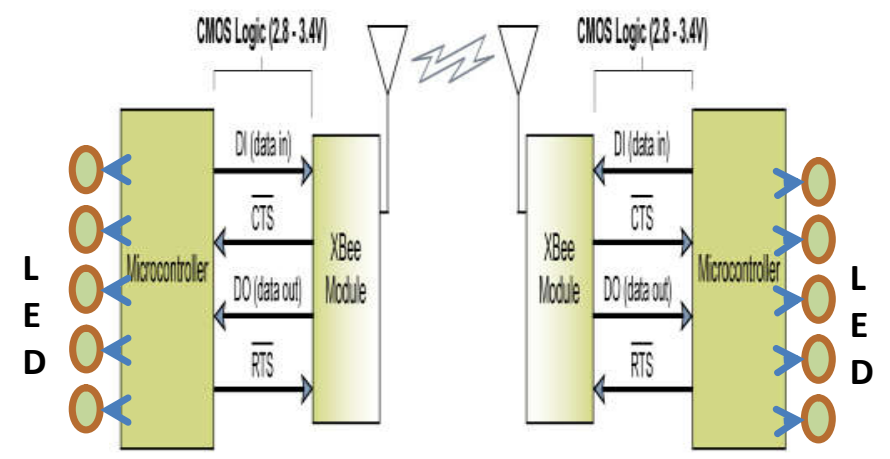

Fig 3. Block system diagram

The workings of the tool are as follows :

a. XBee module as transmitter and receiver, to the squad commanders and each personnel of the team will hold the instrument with the transmitter and receiver and the working principle of the tool client to client.

b. Client to client method is all transmitting and all receive each other at different times during the limits of the range of the transmitter. If more than that then someone will be declared lost or lost contact with LED indicator menyalannya formc. c. The data in the form of analog signals entered and received by each receiver will be included in the microcontroller that will be processed in the microcontroller and displayed in the form of life led as an indicator.

d. Instead the data will be generated by a microcontroller in digital form in the form of binary, which will be transmitted by Xbee module analog signals.

e. Each tool will emit a different address with alternating time and have different ASCII code, so if there are ten people then there will be 10 indicators and 10 different address codes.

f. The process will loop multiply between each other continuously in a period of a few seconds to be arranged in the program inside the microcontroller.

g. Led as indicator that all in transceiver and receiver ring from Module XBee, if it is ignited then it is still not reachable in range area, whereas if die then the transmitter can reach the receiver.

$\mathrm{h}$. On the tool if one of the personnel of the team is missing then one of the led of the 5 led will be lit, while the led indicator is off all then all personnel team is still in the range of other personnel, and on the team personnel lost then led indicator.

Working Principle of Tools Client to Client is described in Figure 3.2.

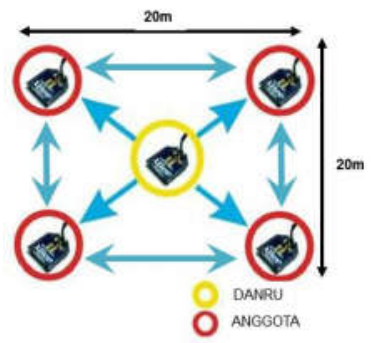

Fig 4. Working Principle of Tools Client to Client

\subsection{System Minimum Design}

In this planning, the microcontroller uses Atmega8 microcontroller, where this microcontroller serves as a tool to process inputs coming from input pins. Aside from being a process tool, the microcontroller also controls the display blocks used as output information. In Figure 3.3 is a series of ATMega 8 microcontrollers, ports used as input and output circuit. 


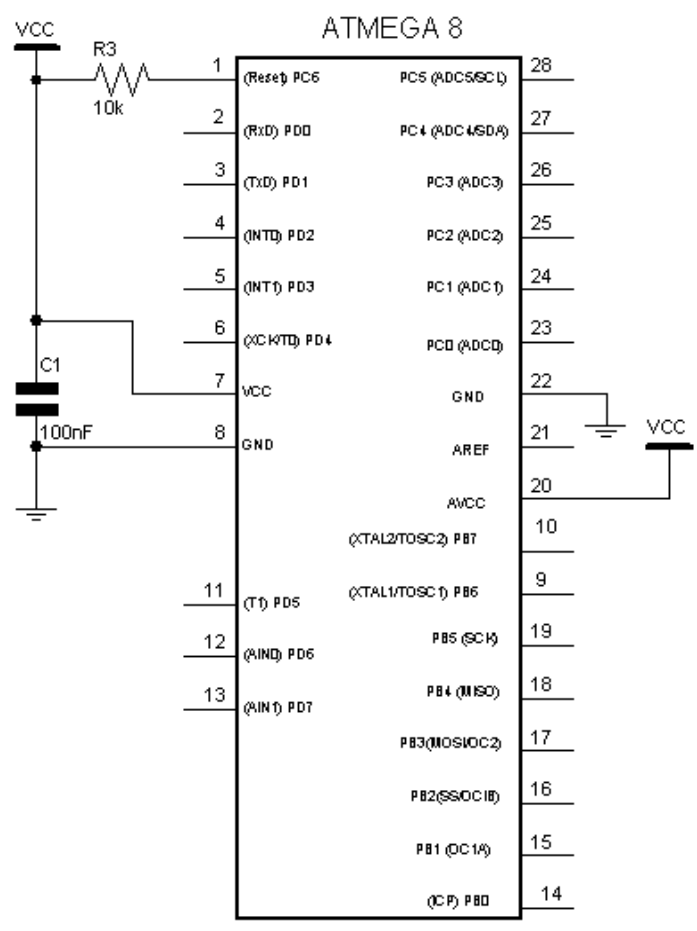

Fig 5. Minimum Circuit of ATMega8 System.

Ports to be used by ATMega8 Microcontroller are as follows:

1. Port D0 s.d Port D7 and Port B6 and Port B7

Port used as LED indicator.

2. Port D0 - D1.

Port used as Tx and Rx.

3. Vec.

Port used as input voltage source of +5 Volt.

4. Ground.

Port Ground is used as ground power supply.

5. AVcc.

Port AVcc connected to Vcc.

6. Reset.

Port C6 as Reset Port is connected to the reset circuit to reset the microcontroller automatically at the time the circuit is turned on and can be reset manually if it is expected to return to its initial state when the microcontroller is working.

\subsection{Designing Regulator Circuit}

The regulator circuit is used to stabilize the incoming voltage on XBee. That is, it lowers the voltage from the power supply from a voltage of $5 \mathrm{~V}$ to $3.3 \mathrm{~V}$, using a zener diode as a voltage divider as shown in Figure 6.

\subsection{Overall Circuit Design.}

The whole design by combining XBee module with microcontroller and LED indicator, become one part and shown in Figure 7.

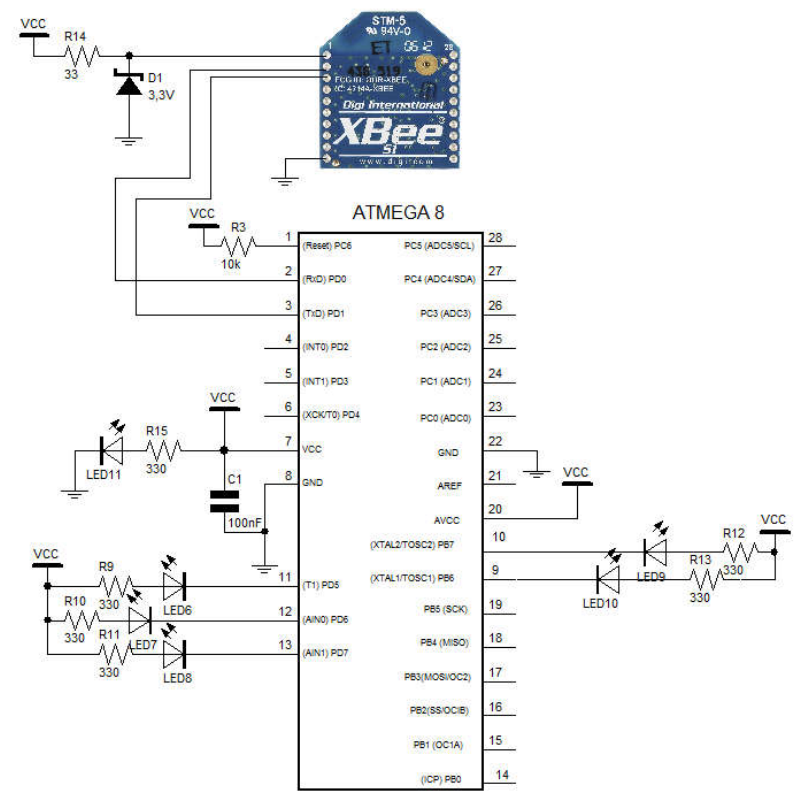

Fig 7 Overall Design

\section{RESULT AND DISCUSSION}

\subsection{Test Result.}

After the program is finished, the next step is to compile the result and enter the program in microcontroller using Downloader. The test results concluded that the LED will be off as a whole for one second, then 5 pieces of LED will live off with 1 second pause in accordance with the program made without any errors, the results of analysis and testing show that the output port on the microcontroller to function properly. Data shown in Table 1., Test images shown in Figure 8

Tabel 1 System Minimum Test Data.

\begin{tabular}{ccccccc}
\hline \multirow{2}{*}{ No } & Device & \multicolumn{5}{c}{ Indicator } \\
\cline { 3 - 7 } & & B6 & B7 & D5 & D6 & D7 \\
\hline $\mathbf{1}$ & 1 & ON & ON & ON & ON & ON \\
\hline $\mathbf{2}$ & 2 & ON & ON & ON & ON & ON \\
\hline $\mathbf{3}$ & 3 & ON & ON & ON & ON & ON \\
\hline $\mathbf{4}$ & 4 & ON & ON & ON & ON & ON \\
\hline $\mathbf{5}$ & 5 & ON & ON & ON & ON & ON \\
\hline
\end{tabular}

Table 4.1 of test data that has been shown, it can be seen that Led can be lit without any obstacles, the pins on Port B and D that will be used to activate the external device can work properly.

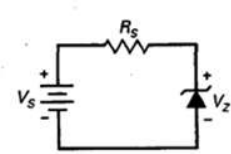

(a)

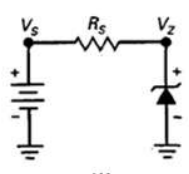

(b)

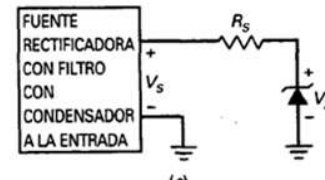

(c)

Fig 6. Regulator Circuit 


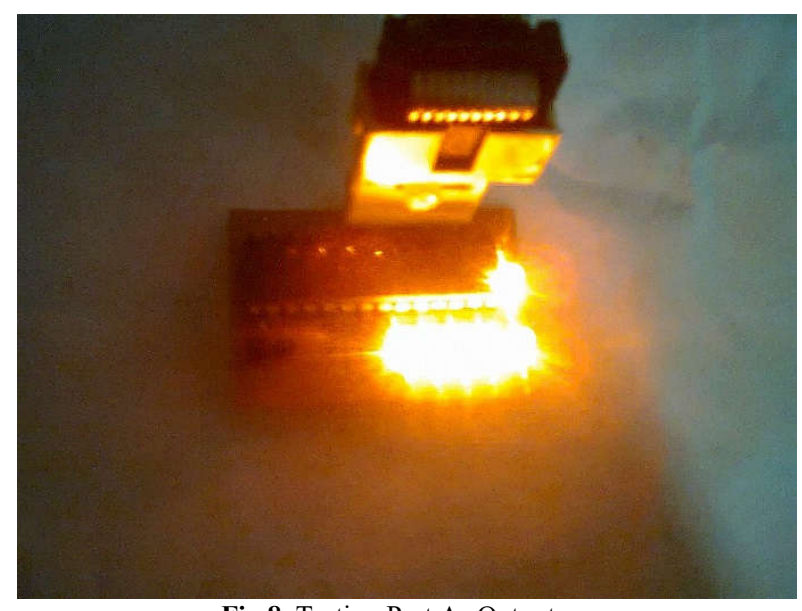

Fig 8 Testing Port As Output.

\subsection{Sistem Minimum Test}

After the program is finished, the next step is to enter the program in microcontroller using Downloader. The test result table is shown in Table 2 with the result of the test result image shown in Figure 10.

Table 2 System Minimum Test Data.

\begin{tabular}{cccccccccccc}
\hline No & Device & \multicolumn{4}{c}{ Push Button } & \multicolumn{6}{c}{ Indicator } \\
\cline { 3 - 11 } & & P5 & P4 & P3 & P2 & P1 & B6 & B7 & D5 & D6 & D7 \\
\hline $\mathbf{1}$ & 1 & Push & Push & Push & Push & Push & on & on & on & on & on \\
\hline $\mathbf{2}$ & 2 & Push & Push & Push & Push & Push & on & on & on & on & on \\
\hline $\mathbf{3}$ & 3 & Push & Push & Push & Push & Push & on & on & on & on & on \\
\hline $\mathbf{4}$ & 4 & Push & Push & Push & Push & Push & on & on & on & on & on \\
\hline $\mathbf{5}$ & 5 & Push & Push & Push & Push & Push & on & on & on & on & on \\
\hline
\end{tabular}

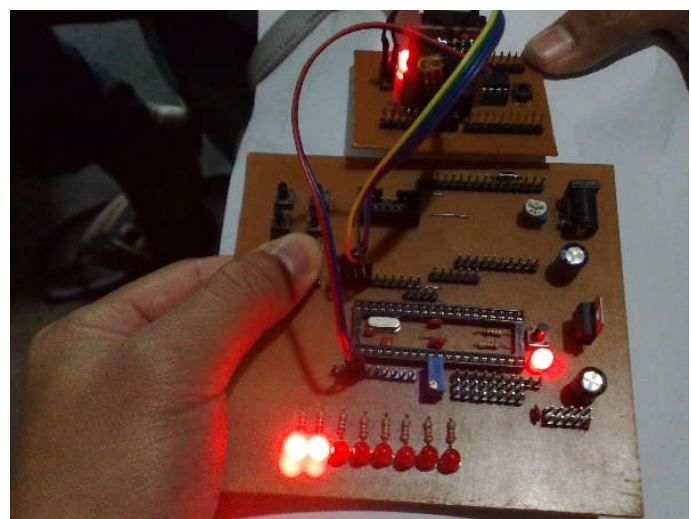

Fig 9. Image of test result port as input of ATmega8.

\subsection{Testing the Regulator Circuit.}

Testing Voltage regulator circuit aims to stabilize the voltage from the microcontroller output to the XBee module because the XBee module requires $2.8 \mathrm{~V}$ to $3.3 \mathrm{~V}$ power supply, while the output from the microcontroller of $5 \mathrm{~V}$. Then the power supply will be stabilized using a voltage regulator circuit using a zener diode. The test is to test the output voltage of the circuit using a zener diode.

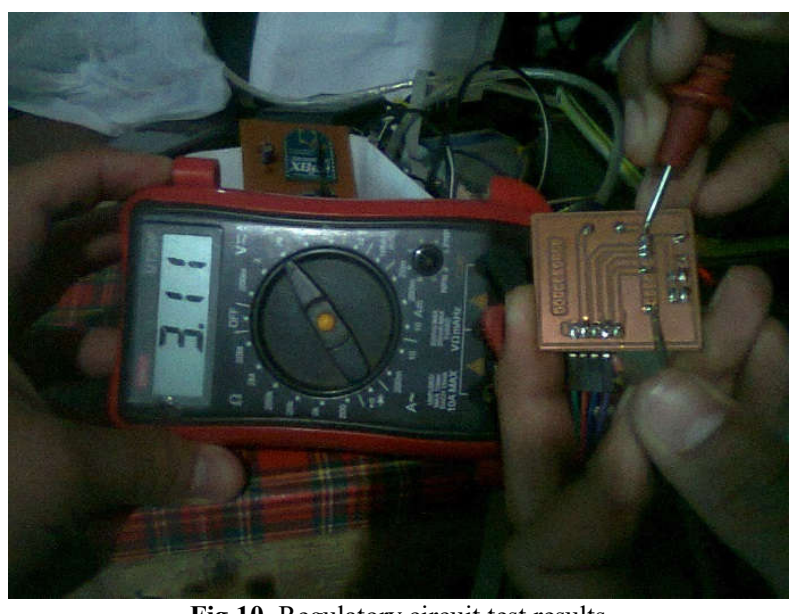

Fig 10. Regulatory circuit test results.

Table 3 Vout test results after passing regulator circuit.

\begin{tabular}{cccc}
\hline No & XBee & $\begin{array}{c}\text { Vin } \\
\text { (Supply) }\end{array}$ & $\begin{array}{c}\text { Vout } \\
\text { (circuit) }\end{array}$ \\
\hline $\mathbf{1}$ & 1 & $6 \mathrm{~V}$ & $3,11 \mathrm{~V}$ \\
\hline $\mathbf{2}$ & 2 & $6 \mathrm{~V}$ & $3,23 \mathrm{~V}$ \\
\hline $\mathbf{3}$ & 3 & $6 \mathrm{~V}$ & $3,15 \mathrm{~V}$ \\
\hline $\mathbf{4}$ & 4 & $6 \mathrm{~V}$ & $3,19 \mathrm{~V}$ \\
\hline $\mathbf{5}$ & 5 & $6 \mathrm{~V}$ & $3,21 \mathrm{~V}$ \\
\hline
\end{tabular}

\subsection{Testing Xbee Module.}

The Xbee module test aims to give addresses to each $\mathrm{XBee}$ and whether XBee can work to send and receive data and ensure that each one is interconnected and ensures the XBee module works properly.

The test results show that the XBee module can transmit data and receive data as well as expected. The XBee Module testing process is shown in Figure 11

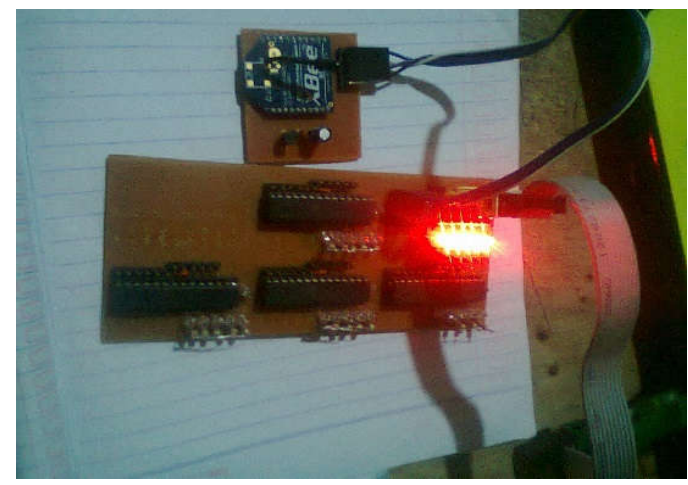

Fig 11 Testing XBee

Table 4 XBee test results using Hyperterminal.

\begin{tabular}{cccc}
\hline No & XBee & Test & Result \\
\hline $\mathbf{1}$ & 1 & Connect & good \\
\hline $\mathbf{2}$ & 2 & Connect & good \\
\hline $\mathbf{3}$ & 3 & Connect & good \\
\hline $\mathbf{4}$ & 4 & Connect & good \\
\hline $\mathbf{5}$ & 5 & Connect & good \\
\hline
\end{tabular}




\subsection{Testing Address.}

Testing Address aims to distinguish one tool with another tool with LED indicator. LEDs live as an inductor of lost or lost contacts and dead LEDs indicate that the team personnel are still in one range from the other.

For the test results can be shown in Table 5 and Figure 12

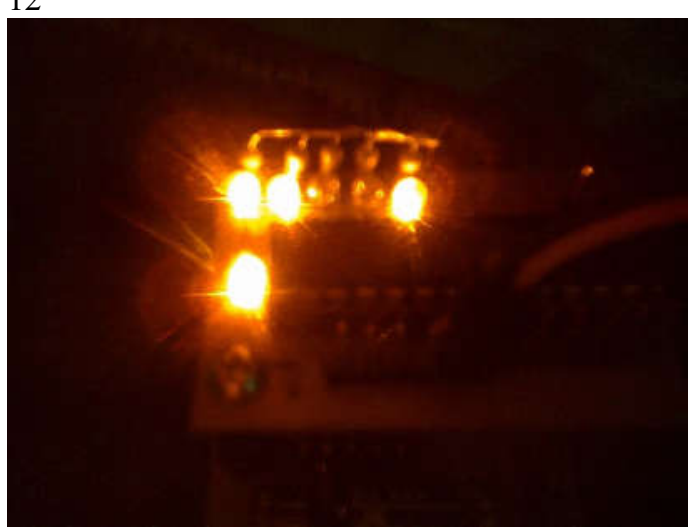

Fig 12 Testing Address.

( Image from testing )

Table 5 Testing Results Address on each tool

\begin{tabular}{cccccccc}
\hline No & device & $\begin{array}{c}\text { ASCII } \\
\text { code }\end{array}$ & $\begin{array}{c}\text { Port } \\
\text { D6 }\end{array}$ & $\begin{array}{c}\text { Port } \\
\text { D6 }\end{array}$ & $\begin{array}{c}\text { Port } \\
\text { D6 }\end{array}$ & $\begin{array}{c}\text { Port } \\
\text { D6 }\end{array}$ & $\begin{array}{c}\text { Port } \\
\text { D6 }\end{array}$ \\
\hline $\mathbf{1}$ & 1 & 49 & ON & OFF & OFF & OFF & OFF \\
\hline $\mathbf{2}$ & 2 & 50 & OFF & ON & OFF & OFF & OFF \\
\hline $\mathbf{3}$ & 3 & 51 & OFF & OFF & ON & OFF & OFF \\
\hline $\mathbf{4}$ & 4 & 52 & OFF & OFF & OFF & ON & OFF \\
\hline $\mathbf{5}$ & 5 & 53 & OFF & OFF & OFF & OFF & OFF \\
\hline
\end{tabular}

\subsection{Overall Testing}

To know the distance from the XBee beam, or the range of the transmitter and receiver can interact with each other. And to know the distance range between the tools one with the other.

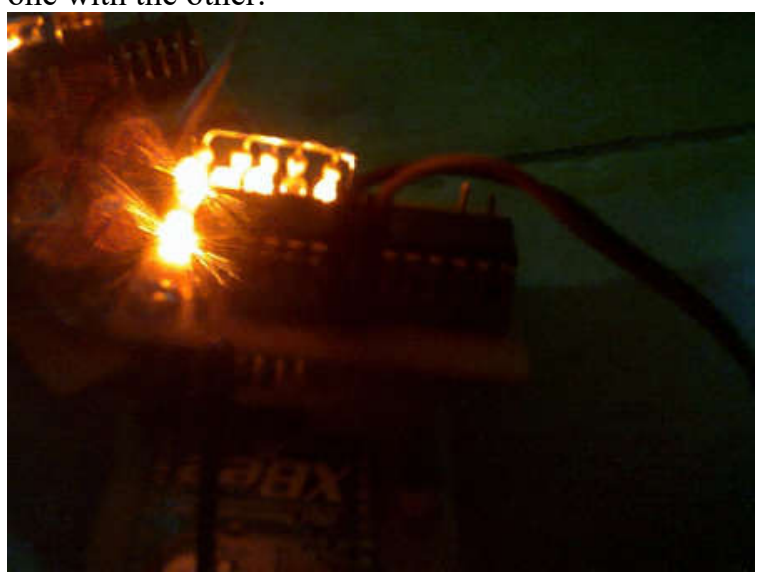

Fig 13 Overall Testing

The image shows that one indicator is off and the other is on. The indicator no 2 aatau tool 2 is still within reach while the three are missing. And one indicator as himself. The indicator will always be on for itself. The results of distance testing can be shown in Table 6 . up to Table 10.
Table 6 Result Test on tool No.1

\begin{tabular}{cccccccccc}
\hline No & Device & \multicolumn{7}{c|}{ Indicator } \\
\cline { 2 - 9 } & & $5 \mathrm{~m}$ & $10 \mathrm{~m}$ & $15 \mathrm{~m}$ & $20 \mathrm{~m}$ & $21 \mathrm{~m}$ & $22 \mathrm{~m}$ & $23 \mathrm{~m}$ & $24 \mathrm{~m}$ \\
\hline $\mathbf{1}$ & 1 & off & off & off & off & off & on & on & on \\
\hline $\mathbf{2}$ & 2 & on & on & on & on & on & on & on & on \\
\hline $\mathbf{3}$ & 3 & off & off & off & off & off & on & on & on \\
\hline $\mathbf{4}$ & 4 & off & off & off & off & off & off & on & on \\
\hline $\mathbf{5}$ & 5 & off & off & off & off & off & off & on & on \\
\hline
\end{tabular}

Table 7 Result Test on tool No.2

\begin{tabular}{cccccccccc}
\hline No & Device & \multicolumn{7}{c}{ Indicator } \\
\cline { 2 - 10 } & & $5 \mathrm{~m}$ & $10 \mathrm{~m}$ & $15 \mathrm{~m}$ & $20 \mathrm{~m}$ & $21 \mathrm{~m}$ & $22 \mathrm{~m}$ & $23 \mathrm{~m}$ & $24 \mathrm{~m}$ \\
\hline $\mathbf{1}$ & 1 & off & off & off & off & off & on & on & on \\
\hline $\mathbf{2}$ & 2 & on & on & on & on & on & on & on & on \\
\hline $\mathbf{3}$ & 3 & off & off & off & off & off & on & on & on \\
\hline $\mathbf{4}$ & 4 & off & off & off & off & off & off & on & on \\
\hline $\mathbf{5}$ & 5 & off & off & off & off & off & off & on & on \\
\hline
\end{tabular}

Table 8 Result Test on tool No.3

\begin{tabular}{cccccccccc}
\hline No & Device & \multicolumn{7}{c}{ Indicator } \\
\cline { 2 - 10 } & & $5 \mathrm{~m}$ & $10 \mathrm{~m}$ & $15 \mathrm{~m}$ & $20 \mathrm{~m}$ & $21 \mathrm{~m}$ & $22 \mathrm{~m}$ & $23 \mathrm{~m}$ & $24 \mathrm{~m}$ \\
\hline $\mathbf{1}$ & 1 & off & off & off & off & on & on & on & on \\
\hline $\mathbf{2}$ & 2 & off & off & off & off & on & on & on & on \\
\hline $\mathbf{3}$ & 3 & on & on & on & on & on & on & on & on \\
\hline $\mathbf{4}$ & 4 & off & off & off & off & off & off & on & on \\
\hline $\mathbf{5}$ & 5 & off & off & off & off & off & off & on & on \\
\hline
\end{tabular}

Table 9 Result Test on tool No.4

\begin{tabular}{cccccccccc}
\hline No & Device & \multicolumn{7}{c}{ indikator } \\
\cline { 2 - 10 } & & $5 \mathrm{~m}$ & $10 \mathrm{~m}$ & $15 \mathrm{~m}$ & $20 \mathrm{~m}$ & $21 \mathrm{~m}$ & $22 \mathrm{~m}$ & $23 \mathrm{~m}$ & $24 \mathrm{~m}$ \\
\hline $\mathbf{1}$ & 1 & off & off & off & off & on & on & on & on \\
\hline $\mathbf{2}$ & 2 & off & off & off & off & on & on & on & on \\
\hline $\mathbf{3}$ & 3 & off & off & off & off & on & on & on & on \\
\hline $\mathbf{4}$ & 4 & on & on & on & on & on & on & on & on \\
\hline $\mathbf{5}$ & 5 & off & off & off & off & off & on & on & on \\
\hline
\end{tabular}

Table 10 Result Test on tool No.5

\begin{tabular}{cccccccccc}
\hline No & Device & \multicolumn{7}{c}{ Indicator } \\
\cline { 2 - 10 } & & $5 \mathrm{~m}$ & $10 \mathrm{~m}$ & $15 \mathrm{~m}$ & $20 \mathrm{~m}$ & $21 \mathrm{~m}$ & $22 \mathrm{~m}$ & $23 \mathrm{~m}$ & $24 \mathrm{~m}$ \\
\hline $\mathbf{1}$ & 1 & off & off & off & off & on & on & on & on \\
\hline $\mathbf{2}$ & 2 & off & off & off & off & on & on & on & on \\
\hline $\mathbf{3}$ & 3 & off & off & off & off & on & on & on & on \\
\hline $\mathbf{4}$ & 4 & off & off & off & off & off & on & on & on \\
\hline $\mathbf{5}$ & 5 & on & on & on & on & on & on & on & on \\
\hline
\end{tabular}

\section{V.CONCLUTION}

Based on the results of planning, making, how to work and testing tools, then taken the following conclusions:

1. TX (transmitter) and RX (receiver) control systems using XBee modules at 20 meters range can still reach the range of devices with each other. but when the distance changed exceeds 23 meters the transmission system and receive data has begun to falter.

2. The sending and transmitting of data on the team movement monitoring tool on the night patrol should distinguish the address on each tool. 


\section{REFERENCES}

[1]. Rangkaian penurun tegangan (diaksaes pada tanggal 22-5-2013)

http://bismarmaulani.blogspot.com/2011/04/diodazener.html

[2]. Datasheet module XBee (diakses pada tanggal 2-52013)

[3]. https://www.sparkfun.com/datasheets/Wireless/Zigb ee/XBee-Datasheet.pdf

[4]. Datasehhet ATmega8 (diakses pada tanggal 29-52013)

[5]. http://www.wvshare.com/datasheet_html/ATmega8PDF.html

[6]. Data mengenai modulasi sinyal (diakses pada tanggal 1-4-2013)

http://id.wikipedia.org/wiki/modulasi. 